\title{
Evaluation of Bond Failure Rate of Orthodontic Brackets Bonded with Green Gloo-Two Way Color Changes Adhesive: A Clinical Study
}

\author{
Zuber Ahamed Naqvi ${ }^{1}$, Saleem Shaikh ${ }^{2}$, Zameer Pasha ${ }^{3}$
}

OPEN ACCESS

Citation: Zuber Ahamed Naqvi, Saleem Shaikh, Zameer Pasha. Evaluation of Bond Failure Rate of Orthodontic Brackets Bonded with Green Gloo-Two Way Color Changes Adhesive: A Clinical Study. Ethiop J Health Sci. 2018;29(2):187. doi:http:// dx.doi.org/10.4314/ ejhs.v29i2.5 Received: October 3, 2018

Accepted: October 11, 2018

Published: March 1, 2019

Copyright: (C) 2019 Zuber A.N., et al. This is an open access article distributed under the terms of the Creative Commons Attribution License, which permits unrestricted use, distribution, and reproduction in any medium, provided the original author and source are credited.

Funding: Bona District Health Bureau and Abem private clinic.

Competing Interests: The authors declare that this manuscript was approved by all authors in its form and that no competing interest exists.

Affiliation and Correspondence:

${ }^{1}$ Department of Preventive Dental Sciences, College of Dentistry, Majmaah University, Majmaah 11952, Saudi Arabia

${ }^{2}$ Department of Oral and Maxillofacial Surgery and Diagnostic Sciences, College of Dentistry, Majmaah University, Majmaah 11952, Saudi Arabia ${ }^{3}$ Department of Oral and Maxillofacial Surgery and Diagnostic Sciences, College of Dentistry, Majmaah University, Majmaah 11952, Saudi Arabia

*Email: zuber2881@gmail.com

\begin{abstract}
BACKGROUND: Bonding is an important step in fixed orthodontic mechanotherapy. Many new materials introduced an adhesive for bonding. This study was designed to evaluate the clinical bond failure rate of orthodontic brackets bonded with green glue: two way color changes adhesive and transbond XT adhesive paste.

METHODS: Eighteen male patients with a mean age of 16 years were included in the study. Convenience sampling technique was used to select the sample for this study. The split-mouth design was used to bond 360 brackets by one operator and both adhesives were used in each patient. Bond failure rates were estimated with respect to bonding procedure, dental arch, tooth type (incisor, canine, and premolar). The results were evaluated using the chisquare test. Kaplan - Meier analysis and the log rank test were used to estimate the survival rate of the brackets. Bracket failure rates for each system were analyzed, and failure causes as reported by the patients and the quadrant of each tooth in which brackets failed were recorded.

RESULTS: The bond failure rate was $5.00 \%$ and $4.44 \%$ for green gloo and transbond $X T$ group. No significant difference was found in the bond failure rate between transbond $X T$ and Green gloo group. No significant difference was found in the bond failure rate between the two groups, in relation to right and left side and the type of teeth.

CONCLUSION: Green gloo adhesive can be effectively used to bond orthodontic brackets.

KEYWORDS: Bond failure rate, adhesive, orthodontic brackets, green gloo, transbond XT.
\end{abstract}

\section{INTRODUCTION}

The science of orthodontics is rapidly evolving with advancement of new materials. Particularly in the field of bonding, many new materials like new adhesives, sophisticated base designs, and new bracket materials, faster or more efficient curing methods, selfetching primers, fluoride-releasing agents and sealants adhesive were introduced for bonding orthodontic brackets (1). 
Bonding is the initial step in the treatment of a patient by fixed orthodontic appliance. With the introduction of preadjusted edgewise brackets to the orthodontics number of bends is required in archwire reduced to treat a patient because the first, second and third order bends were incorporated within the brackets. Hence, the placement of orthodontic appliance is possibly the most important mechanical procedure in the treatment of orthodontic patients. As the finishing stages are approached, proper placement of brackets can result in cases which begin to occlude quite satisfactorily with little effort, while improper bracket positions can result in cases which require several extra months of finishing and detailing (2).

Crypsis, a color-change adhesive, was introduced in 1986. This 2-paste dual-cure bracket adhesive was developed and marketed by areas (Beaverton, Ore). The 2-paste material was yellow after it was mixed and during the gel period, but it turned tooth color when it polymerized. The color-change mechanism was a function of the light-cure catalyst. In 2004, several single-best light-cured, color changing adhesives entered the market from Reliance Orthodontic Products, 3M Unitek, and Ormco. The color-change mechanism in the bracket adhesive from Ormco was temperature induced and could be reversed to show adhesive remnants left behind at depending by simply introducing cold water into the oral environment. This color characteristic allowed the operator to see the composite flash around the bracket base and remove it before it polymerized.

The clinical performance of bonding adhesive should be assessed by clinical bond failure studies because the oral environment cannot be created in the laboratory (3). Now, the examined variable is the actual survival of bonds; hence, clinical bond failure studies have become popular (4). Previously, many studies have been published concerning bond failure rates of different types of adhesive paste (5). The commonly used materials in previous studies were Two-stage conventional systems (acid etching + Transbond XT adhesive primer) and a single stage self-etching primer (SEP) (Transbond
Plus) (4-11). The purpose of this work was to compare the bond failure rate of stainless steel brackets bonded with two different adhesive pastes.

\section{MATERIALS AND METHODS}

The study was approved by the Ethical Committee of College of Dentistry, Zulfi. Eighteen male patients with a mean age of sixteen years were selected for this study. Convenience sampling technique was used to select the sample for this study. Sample size was determined by the number of subjects enrolled in the study over a period of one month. Patients included in the study needed corrective orthodontics with no history of orthodontic treatment. The buccal surface of teeth should be free of any restoration or hypoplastic lesion. Malocclusion differences were ignored; hence, patients with all types of malocclusion were included in the sample of this study. The exclusion criteria were tooth extraction or orthognathic surgical treatment required for correction of malocclusion, crown, congenital enamel defects, missing teeth, craniofacial anomalies or patients with low IQ who were unable to maintain oral hygiene.

At the beginning of fixed orthodontic mechanotherapy, all the patients were instructed to maintain oral hygiene and care of their braces. Total 360 (180 in each group) metallic 0.022 slot MBT brackets were bonded by a split-mouth technique. Each patient's mouth was divided into four quadrants. Brackets were bonded by randomly alternating contralateral bonding pattern among the patients which ensures equal distribution of enamel treatments between the right and left sides (9).

In both the groups, same bracket bonding protocol was followed. Before bonding, oral prophylaxis was performed by using a low speed handpiece along with rubber cup, pumice and water spray followed by rinsing with water. Cheek Retractors were used to obtain isolation. MBT tables were used to place the brackets at an accurate location on the buccal surface of all the teeth mesial to first molar in each quadrant.

For bonding, with both the adhesive paste same steps were followed, i.e. etching with $37 \%$

DOI: http://dx.doi.org/10.4314/ejhs.v29i2.5 
phosphoric acid, rinsing, drying, priming (application of bonding agent), bracket placement with adhesive at the base of the bracket and curing. The tooth surface was etched using 37\% phosphoric acid for 30 seconds followed by rinsing and drying for 5 and 10 second; then respective bonding agents were applied in thin layers. A thin layer of adhesive was paste applied to the base of the bracket. After removing excess resin, both the adhesive paste was cured according to the manufacturer's instructions by using halogen light. Curing time for transbond $\mathrm{XT}$ was 10 seconds and to green glue two wayscolor change was 20 seconds.

Initial arch wire (0.014 inch NiTi) for leveling phase was placed on the same day in both upper and lower arches. Patients were instructed for proper appliance cleaning and care, specifically to avoid foods and habits that may damage the appliance.

Patients were asked to check for debonded brackets daily. If any bracket debonded, they were instructed to write the date of bracket failure and to visit the clinic immediately. Patients were seen after every four weeks. Only the first bond failure was recorded for each bracket.

Bond failure rates for the first 24-months periods were determined for each bonding procedure. The chi-square test was applied to compare failure rates $(\mathrm{P}<0.05)$. Kaplan-Meier estimates of bracket survival curves were plotted. Log-rank test $(\mathrm{P}<0.05)$ was used to compare bracket survival distributions with respect to bonding procedure, dental arch and type of tooth (incisor, canine and premolar).

\section{RESULTS}

At the end of the 24 months, a total of 17 brackets were debonded. The bond failure rate in transbond group was $4.44 \%$ (8 out of 180) and in green gloo was 5\% (9 out of 180) (Tables 1 and 2 ). The difference in bond failure rate between the groups was found statistically non-significant ( $p>0.05$, Tables 2, Graph 1). Bond failure rate was compared according to type of teeth, right and left quadrant and upper and lower dental arch, and the differences was statistically nonsignificant ( $p>0.05$, Tables 1 and 2, Graph 1). Kaplan-Meier survival plots also showed no statistically significant differences in failure rate between group A and group B (Figure 1a) according to the tooth type (Figure $1 \mathrm{~b}$ ), quadrant of dental arch (Figure 1c) and upper and lower arch (Figure 1d). A non-significant difference was found in bracket survival rate between the transbond and green gloo group (Table 3 ).

Table 1: Comparative bond failure rates classified according to tooth and bonding system in the upper and lower arch

\begin{tabular}{|c|c|c|c|c|}
\hline \multirow[t]{2}{*}{ Tooth } & \multicolumn{2}{|c|}{ Right quadrant } & \multicolumn{2}{|c|}{ Left Quadrant } \\
\hline & Conventional resin & $\begin{array}{l}\text { Experimental } \\
\text { resin }\end{array}$ & $\begin{array}{l}\text { Conventional } \\
\text { resin }\end{array}$ & $\begin{array}{l}\text { Experimental } \\
\text { resin }\end{array}$ \\
\hline Upper incisors & 0 & 1 & 1 & 0 \\
\hline Upper canines & 0 & 0 & 0 & 1 \\
\hline Upper premolars & 1 & 2 & 2 & 1 \\
\hline Lower incisors & 1 & 0 & 1 & 1 \\
\hline Lower canines & 0 & 0 & 0 & 0 \\
\hline Lower premolars & 1 & 1 & 1 & 2 \\
\hline Total & 3 & 4 & 5 & 5 \\
\hline
\end{tabular}

Table 2: Log rank and Chi square test used to compare difference in bond failure rate.

DOI: http://dx.doi.org/10.4314/ejhs.v29i2.5 


\begin{tabular}{|c|c|c|c|c|c|c|}
\hline Groups & $\begin{array}{l}\text { Brackets } \\
\text { bonded }\end{array}$ & $\begin{array}{l}\text { Bond } \\
\text { failure }\end{array}$ & $\begin{array}{l}\text { Failure rate } \\
\%\end{array}$ & $\begin{array}{l}\text { Log - rank } \\
\text { test }\end{array}$ & $\mathrm{df}$ & $\begin{array}{l}\text { Chi } \\
\text { square }\end{array}$ \\
\hline $\begin{array}{l}\text { Conventional } \\
\text { resin }\end{array}$ & 180 & 8 & 4.44 & 0.817 & 1 & 0.054 \\
\hline $\begin{array}{l}\text { Experimental } \\
\text { resin }\end{array}$ & 180 & 9 & 5.00 & & & \\
\hline Canine & 72 & 1 & 1.39 & 0.028 & 2 & 7.167 \\
\hline Incisor & 144 & 4 & 2.78 & & & \\
\hline PM & 144 & 12 & 8.33 & & & \\
\hline $\begin{array}{l}\text { Left } \\
\text { quadrant }\end{array}$ & 180 & 11 & 6.11 & 0.221 & 1 & 1.495 \\
\hline $\begin{array}{l}\text { Right } \\
\text { quadrant }\end{array}$ & 180 & 6 & 3.33 & & & \\
\hline Lower & 180 & 8 & 4.44 & 0.790 & 1 & 0.071 \\
\hline Upper & 180 & 9 & 5.00 & & & \\
\hline
\end{tabular}

Table 3: Chi square test used to compare difference in survival rate

\begin{tabular}{lllll}
\hline Group & Brackets bonded & No failure & Survival rate & Chi square test \\
Conventional resin & 180 & 172 & 0.956 & 0.957 \\
Experimental resin & 180 & 171 & 0.950 & \\
\hline
\end{tabular}

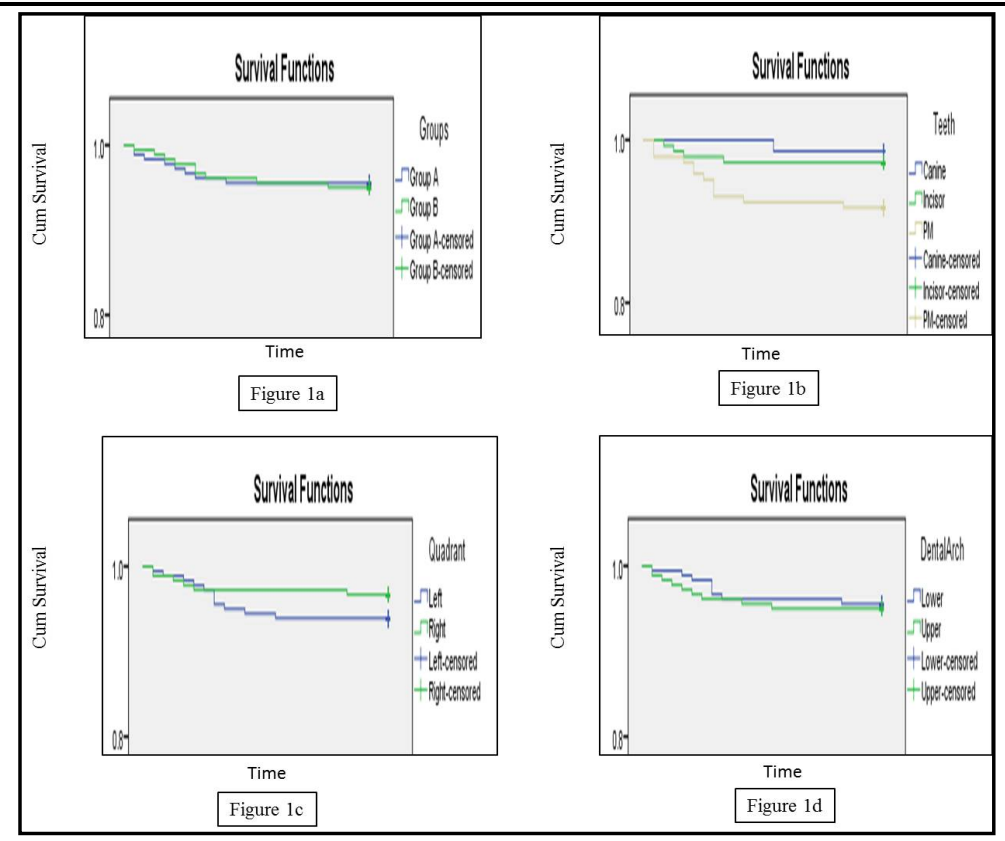

Figure 1: Kaplan-Meier survival plots showed no statistically significant differences in failure rate between group A and group B (Figure a) according to the tooth type (Figure 1b), quadrant of dental arch (Figure 1c) and upper and lower arch (Figure 1d) 


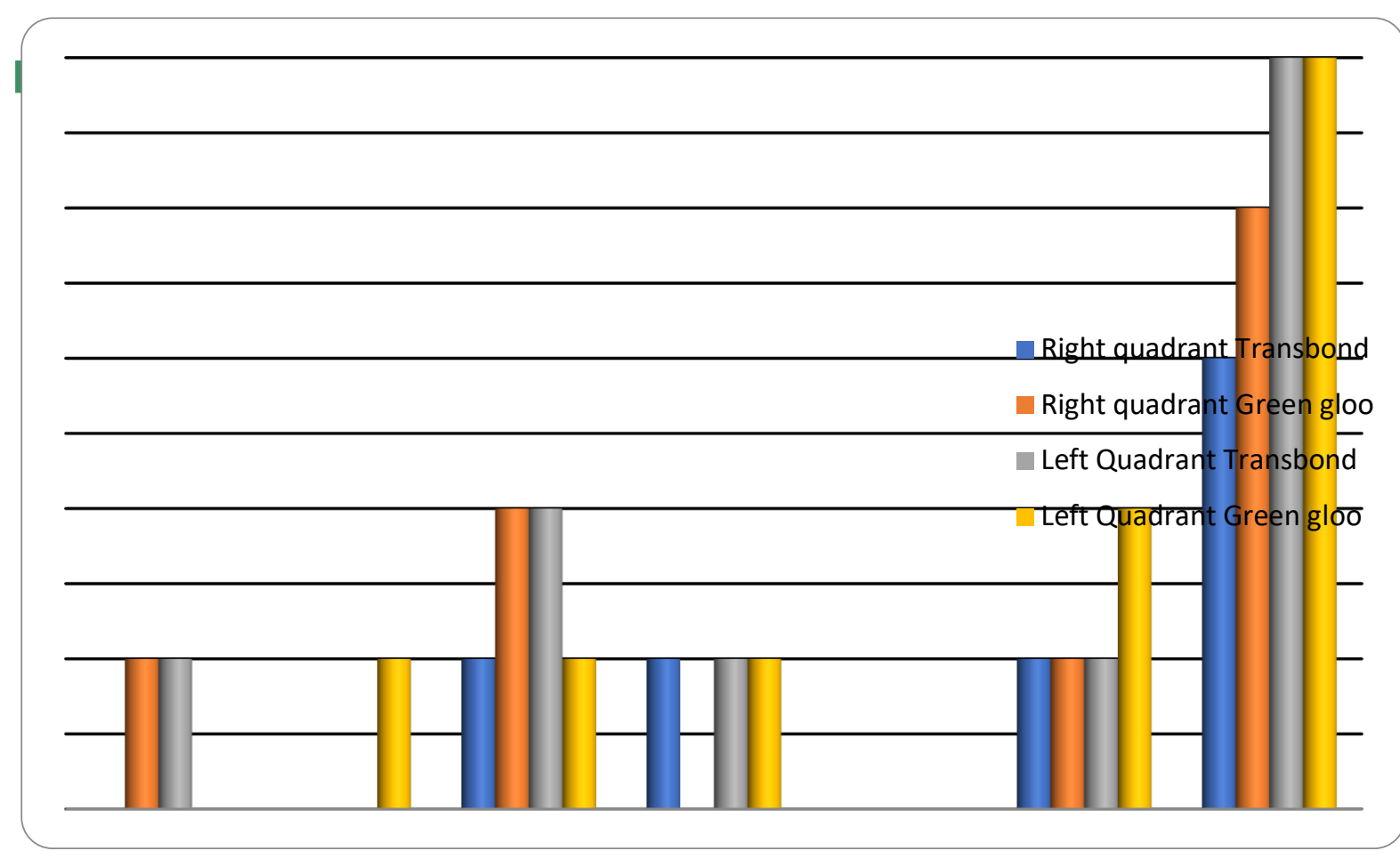

Graph 1: Comparative bond failure rates classified according to tooth and bonding system in the upper and lower arch

\section{DISCUSSION}

Today, there are different types of orthodontic bonding materials available like self-cure light cure, bonding material with self-etch primers, color change adhesive, etc. These materials are introduced to clinics after certain initial test; one of the important test is shear bond strength to dental enamel. The bonding procedure done in laboratory differs significantly as compared to the bonding done in the patient's mouth due to integral factors isolation, location and accessibility and other components of oral cavity like tongue, cheek, lips, etc. The bonding technique becomes more difficult in the oral cavity and affects the quality of adhesion between the bracket base and tooth surface. Hence, the clinical trial of any material is crucial so that its characteristics and performance can be evaluated prior to recommending it (12).

Conventional resin is easy to handle and has good adhesiveness with long working time. Due to these properties, it is the most common material used as a control in vitro (13-18) and in vivo (15-19) studies. Ekhlassi et al (20) and Duers MW et al (21) conducted in vitro studies on color- change adhesive to evaluate the bond strength, and they concluded that color-change adhesive also demonstrated adequate bond strength to withstand orthodontic forces. Scribante et al (22) concluded that though in vitro bonding studies represent one of the first steps of materials testing and should be followed by in vivo clinical studies in order to confirm the in vitro results. There is lack of in vivo studies on color change adhesive. This study represents the first study evaluating in vivo clinical efficacy of experimental resin compared to a conventional one.

To evaluate the effectiveness of bonding by using experimental resin, brackets were bonded by a split -mouth technique as this technique has been widely used in orthodontic research as a reliable method to test different variables such as flowable composites by Krishnan et al (23), composites containing nano amorphous calcium phosphate by Jahanbin et al (24), plasma arc and halogen curing unit light by Cacciafesta et al (25), reconditioned bracket failure rate by Cacciafesta et al (26), adhesive coated brackets failure rate et al by Kula K et al (27).

In our study, bond failure rate of conventional resin was observed $4.44 \%$ (Table 1 , Graph 1). This result is not similar to previously

DOI: http://dx.doi.org/10.4314/ejhs.v29i2.5 
done studies. The results of all the studies were not similar. Some studies found bond failure rate of less than our study like Murfitt et al (10), CalNeto and Miguel (9) observed 3.9\% and 2.54\%, whereas some studies like Asgari et al (8), Manning et al (28), Reis A et al (29), Santos et al (30) and Ireland et al (31) observed higher bond failure rate i.e. $4.95 \%, 7.4 \%, 17.6 \%, 4.60 \%$ and $10.6 \%$ respectively.

In clinical studies (8-10, 30-31), differences in failure rates and contradictory results are noteworthy. Due to lack of standardized protocol, the results of clinical comparative studies should be interpreted cautiously (32-33). In in vivo studies, patient factors like malocclusion classification, masticatory forces varying with facial type, socioeconomic and dental status of patients, culturally influenced dietary habits; sex differences may affect the outcomes (4).

After 24 months, bond failure rate of experimental resin was higher $(5.00 \%)$ than conventional resin $(4.44 \%)$. This difference was statistically non-significant as shown by log- rank test and chi square test $(p<0.05)$ (Table 2, Figure $1)$.

In this study, it was found that the survival rates were 0.956 and 0.950 for the conventional experimental and experimental resin group respectively. A survival rate of 0.956 means bonded bracket has $95.6 \%$ chance to still be in place after 24 months for the conventional resin. The experimental resin had a $95.0 \%$ chance to be in place after 24 months(Table 3 ).

Out of total 17 bond failures, most failures occurred in premolars i.e. 14 followed by other teeth (Table 1, Graph 1). The difference in bond failure according to type of teeth is statistically not significant (Table 1 and 2, Figure 1 and Graph 1). Our findings are in consistent with previous studies which showed the bond failure is more with posterior teeth than for anterior teeth $(6,10$, 34- 35). The fact that premolars are the teeth with the highest rate may be explained as a result of several factors: Lower risk of contamination by humidity in the anterior region during bonding; occlusal forces that exceed the limits of adhesive resistance of the brackets; greater amount of prism less enamel, which may affect the quality of micromechanical bonding and result in poor adhesion; and the difficulty to isolate the posterior region (5).

A number of failures occur on the left side (10 i.e. $5.556 \%$ ) was greater as compared to the right side ( 7 i.e. $3.889 \%$ ). This difference was statistically non-significant (Table 1 and 2, Figure 1, Graph 1). Our results are in agreement with most of previous studies $(4,20,36)$, but not in agreement with few studies (37). One possible explanation for that might be the patients' masticatory habits (38).

No significant difference was found in the bracket failure rate between upper and lower arch (Table 2, Figure 1). These results are similar to the results of clinical studies conducted by Pandis et al (38) and Mavropoulos et al (39). In the this study, premolar teeth demonstrate significantly higher failure rates and lower survival rates. Mavropoulos et al (39) observed that the bracket failure rate for posterior teeth (first and second premolars) was three times higher than the failure rate for anterior teeth (incisors and canine). These higher failures were attributed to occlusal interferences.

In conclusion the bonding efficiency of experimental resin was not significant different than conventional resin. Hence, experimental resin can be effectively used to bond orthodontic brackets in patients.

\section{ACKNOWLEDGEMENTS}

I would like to thank Deanship of Scientific Research at Majmaah University for supporting this work.

\section{REFERENCES}

1. Paul G. The evolution of bonding in orthodontics. Am $J$ Orthod Dentofacial Orthop 2015; 147: S56-63.

2. John CB, Richard PM, 2001, Orthodontic treatment mechanics and the preadjusted appliance, $I^{\text {st }}$ edition, Mosby International Ltd.

3. House K, Ireland AJ, Sherriff M. An investigation into the use of a single component self- etching primer adhesive

DOI: http://dx.doi.org/10.4314/ejhs.v29i2.5 
system for orthodontic bonding: a randomized controlled clinical trial. Journal of Orthodontics 2006; 33:38-44.

4. Pandis N, Eliades T. A comparative in vivo assessment of the long-term failure rate of 2 self-etching primers. Am $J$ Orthod Dentofacial Orthop 2005; 128:96-98.

5. Gladys CD, Andre T, Luiz VDML, Priscilla CCC, Camillo M. A comparative clinical study of the failure rate of orthodontic brackets bonded with two adhesive systems: Conventional and Self-Etching Primer (SEP). Dental press journal 2013; Mar-Apr; 18(2):55-60.

6. Elekdag TS, Cakmak F, Isci D, Turk T. 12month self-ligating bracket failure rate with a self-etching primer. Angle Orthod 2008; 78(6):1095- 100.

7. Vijayakumar RK, Raju J, Fayyaz A, Aprose K, Suresh K. How and why of orthodontic bond failures: An in vivo study. $J$ Pharm Bioallied Sci. 2014; Jul; 6 (Suppl 1): S85S89.

8. Asgari S, Salas A, English J, Powers J. Clinical evaluation of bond failure rates with a new self-etching primer. $J$ Clin Orthod 2002; 36: 687-689.

9. Cal-Neto JP, Miguel JA. An in vivo evaluation of bond failure rates with hydrophilic and self-etching primer systems. J Clin Orthod 2005; 39:701-702.

10. Murfitt PG, Quick AN, Swain MV, Herbison GP. A randomized clinical trial to investigate bond failure rates using a self-etching primer. European Journal of Orthodontics 2006; 28(5): $444-9$.

11. Manning N, Chadwick SM, Plunkett D, Macfarlane TV.A randomized clinical trial comparing 'one-step' and 'two-step' orthodontic bonding systems. Journal of Orthodontics 2006; 33: 276 - 283.

12. Romano FL, Américo BC, Lourenço CS, Maria BBDAM, AntônioCDOrR. Clinical evaluation of the failure rates of metallic brackets. J Appl Oral Sci 2012; 20(2):228-34.

13. Cacciafesta V, Sfondrini MF, De Angelis M, Scribante A, Klersy C .Effect of water and saliva contamination on shear bond strength of brackets bonded with conventional, hydrophilic, and self-etching primers. $\mathrm{Am} \mathrm{J}$ Orthod Dentofacial Orthop. 2003; 123:63340.

14. Dorminey JC, Dunn WJ, Taloumis LJ. Shear bond strength of orthodontics brackets bonded with a modified 1-step etchant-and primer technique. Am J Orthod Dentofacial Orthop 2003; 124:410-3.

15. Grandhi K, Combe EC, Speidel TM. Shear bond strength of stainless steel orthodontic brackets with a moisture-insensitive primer. Am J Orthod Dentofacial Orthop 2001; 119:251-5.

16. Grubisa HS, Heo G, Raboud D, Glover KE, Major PW. An evaluation and comparison of orthodontic bracket bond strengths achieved with self-etching primer. Am J Orthod Dentofacial Orthop 2004; 126:213-9.

17. Romano FL, Correr-Sobrinho L, Magnani MBBA, Nouer DF, Sinhoretti MAC, Correr AB. Shear bond strength of metallic brackets bonded under various enamel conditions. Braz Oral Res 2006; 20(Spec Iss):28-33.

18. Romano FL, Tavares SW, Nouer DF, Consani S, Magnani MBBA. Shear bond strength of metallic orthodontic brackets bonded to enamel prepared with self-etching primer. Angle Orthod. 2005; 75:849-53.

19. Elekdag TS, Isci D, Turk T, Cakmak F. Sixmonth bracket failure rate evaluation of a self-etching primer. Eur J Orthod 2008; 30:211-6.

20. Sara E, Jeryl DE, Joe C, Ontiveros el al. Bond strength comparison of color-change adhesives for orthodontic bonding using a self-etching primer. Clinical, Cosmetic and Investigational Dentistry 2011; 3:39-44.

21. Duers MW, English JD, Ontiveros JC. Bond strength comparison of color change adhesives for orthodontic bonding. Tex Dent $J$ 2011;128 (3):267-75.

22. Andrea S, Rosalia CB, Mona A. Montasser,Pekka KV. Orthodontics: bracket materials, adhesives systems, and their bond strength. BioMed Research International 2016; 1-3.

DOI: http://dx.doi.org/10.4314/ejhs.v29i2.5 
23. Krishnan S, Pandian S, Rajagopal R. Sixmonth bracket failure rate with a flowable composite: A split-mouth randomized controlled trial. Dental Press J Orthod. 2017 Mar-Apr; 22(2):69-76.

24. Jahanbin A, Farzanegan F, Atai M, Jamehdar SA, Glfakhrabadi P, Shafaee H. A comparative assessment of enamel mineral content and Streptococcus mutans population between conventional composites and composites containing nano amorphous calcium phosphate in fixed orthodontic patients: a split-mouth randomized clinical trial. European Journal of Orthodontics 2017; 39(1):43-51.

25. Cacciafesta V, Sfondrini MF, Scribante A. Plasma arc versus halogen light-curing of adhesive-precoated orthodontic brackets: a 12-month clinical study of bond failures. $\mathrm{Am}$ J Orthod Dentofacial Orthop 2004; 126:1949.

26. Cacciafesta V, Sfondrini MF, Melsen B, ScribanteA. A 12 month clinical study of bond failures of recycled versus new stainless steel orthodontic brackets. Cacciafesta V, Sfondrini MF, Melsen B, Scribante A. Eur J Orthod. 2004 Aug;26(4):449-54.

27. Kula K, Schreiner R, Brown J, Glaros A. Clinical bond failure of pre-coated and operator-coated orthodontic brackets. Orthod Craniofac Res. 2002 Aug;5(3):161-5.

28. Manning N, Chadwick SM, Plunkett D, Macfarlane TV. A randomized clinical trial comparing "one step" and "two step" orthodontic bonding systems. J Orthod 2006; 33:276-83.

29. Reis A, Santos JE, Loguercio AD, Bauer JRO. Eighteen-month bracket survival rate: conventional versus self-etch adhesive. EurJ Orthod 2008; 30:94-9.

30. Santos JE, Quioca J, Loguercio AD, Reis A. Six-month bracket survival with a self-etch adhesive. Angle Orthod 2006; 76:863-8.
31. Ireland AJ, Knight H, Sherriff M. An in vivo investigation into bond failure rates with a new self-etching primer system. Am J Orthod Dentofacial Orthop 2003; 124:323-326.

32. O'Brien KD, Read MJ, Sandison RJ, Roberts CT. A visible light-activated direct-bonding material: an in vivo comparative study. $\mathrm{Am} \mathrm{J}$ Orthod Dentofacial Orthop 1989; 95:348351.

33. Pashley DH, Tay FR. Aggressiveness of contemporary self-etching adhesives part II: etching effects on unground enamel. Dent Mater. 2001; 17:430-444.

34. Barry GRP. A clinical investigation of the effects of omission of pumice prophylaxis on band and bond failure. $J$ Orthod. 1995; 22(3):245-8.

35. Sunn S, Rock W. Clinical performance of orthodontic brackets and adhesive system: a randomized clinical trial. J Orthod. 1998; 25(4):283-7.

36. Moin K. Indirect bonding of orthodontic attachments.Am J Orthod. 1977; 72:261.75.

37. Banks P, Thiruvenkatachari B. Long-term clinical evaluation of bracket failure with a self-etching primer: a randomized Controlled trial. J Orthod 2007; 34: 243-51.

38. Pandis N, Polychronopoulou A, Eliades T. Failure rate of self-ligating and edgewise brackets bonded with conventional acid etching and a self-etching primer. Angle Orthod. 2006; 76(1):119-22.

39. Mavropoulos A, Karamouzos A, Kolokithas $\mathrm{G}$, Athanasiou AE. In vivo evaluation of two new moisture-resistant orthodontic adhesive systems: a comparative clinical trial. J Orthod 2003; 30:139-147.

DOI: http://dx.doi.org/10.4314/ejhs.v29i2.5 